\title{
A Guide to Map Sources for Use in Building a College Map Library
}

$\mathrm{I}^{\mathrm{N}}$ A previous article basic principles for planning the scope and content of a college map library were outlined. This article is designed to help the librarian implement the program evolved. The intent is not to provide even a partial list of map sources or agencies. In fact, no such list exists and if it did it would require several volumes. The intent instead is to introduce the librarian to the types of map sources, their nature, and the peculiar problems related to them, and to current bibliographic aids and methods by which he can keep abreast of map publications.

The college librarian buying books has many advantages compared to one purchasing maps. He has a variety of well-established aids at hand, including cumulative book lists and lists of current publications.

The bulk of his material is published in the United States; certain concerns specialize in assembling obscure items. Also, faculty members frequently are able to provide precise information and specific titles. In contrast, the librarian purchasing maps is faced with special problems. The solution to many of them is time-consuming and is one of the reasons that maps have been neglected by libraries. In the first place, he has no single guide to published maps or to new maps being published. Secondly, the bulk of his material is issued in foreign countries. The signs and conventions on maps provide virtually an international language, and language is no barrier to the use of maps. Most of the maps, both specialized and general, which pertain to a given area will be published by agencies within the country in which the area is located. Thus, whereas a suitable group of books on Germany in English might be obtained in this country, maps (with the exception of a few small-scale general ones) must be purchased for the most part in Germany. Purchasing of most maps, therefore, is complicated by all the problems of foreign acquisition. This also explains in part the lack of information concerning the publication of maps. It is buried within the publications of many countries and is locked therein by language barriers.

A third problem is made concrete to the librarian when he realizes that the terms "fugitive" and "documentary" materials are applicable particularly to maps. Most maps are published by official government agencies and many maps are serial publications. Large- and medium-scale map series are usually published over a period of years. The topographic map of the United States has been in the process of publication for more than seventy years and is only about half completed. Within that time some sheets have been published in several editions. The inability of many libraries to maintain complete files even of selected United States documentary items suggests the difficulties with which the map librarian is faced when assembling foreign documentary materials. Use of the term "fugitive" as applied to maps indicates their evanescent nature. They lack durability 
and as working tools are consumed in many cases. The latter is evidenced by the tremendous map consumption during World War II. There are already cases of important maps known to have been published during the war of which only a few copies or no copies now exist. In addition, some maps are prepared for a special purpose or deal with a topic of temporary interest. As a result, information as to their existence is limited and only a few copies (perhaps photographic prints) are made. Examples of such items are maps prepared to illustrate reports by federal agencies during the last war and county and city maps used by local officials for administrative purposes.

\section{Problems}

Finally, the college librarian buying maps obtains little help from faculty members and purchasing agencies. The faculty member wanting a book on a particular subject usually will provide the title and author. In contrast, when he needs a map he is apt to ask merely for a map showing certain information. Limited knowledge concerning the existence of maps and publishing agencies, the small demand for maps, their great number and variety, and the relatively high cost of acquisition compared to the cost of the map itself have prevented the establishment of agencies specializing in their procurement. That these problems are real and involve considerable expense is evidenced by the elaborate organizations which must be maintained by such large modern map collections as the Army Map Service and the State Department. Both rely on regional field specialists who travel from place to place, in addition to the consuls and military attachés in various countries.

Increased interest in the development of map collections by colleges and universities in the last few years obviously has resulted in a greatly expanded interest in map sources. There are thousands of map sources, many more than for books. In the United States each of more than three thousand county surveyors is a potential producer of a map; so are each of the thousands of city engineers. This multitude of possible sources is almost certain to be confusing. Only if a concise plan covering the nature and scope of the map library has been formulated in terms of areas, subjects, and scales, can the librarian hope to overcome the peculiar problems of map sources and acquisition. In this manner his attention is focused on particular types and series of maps. With a general knowledge of the nature of map-producing agencies, he can then proceed to acquire specific information and map items. Map sources are analyzed in the following pages, with emphasis on sources in the United States. The statements made are applicable to map sources in other countries also, but to a lesser degree. In general, the higher the cultural and material development of a country, the greater are the number and variety of maps available for that country.

\section{Map Sources}

There are three main types of map sources or map-issuing agencies: governmental or official agencies, commercial publishers or private agencies, and scientific societies, institutes, and organizations. The classification is significant because each publishes different types of maps for the most part and each presents different problems in connection with acquisition of its material.

Governmental or official map agencies are greatest in number and importance. Probably 90 per cent of all different map items published are issued by official government agencies. Included among government agencies are not only all the various federal departments, bureaus, and other 
administrative subdivisions, but also the various administrative divisions of states (provincal, departmental, etc., in some countries), counties, and other minor civil divisions (townships, cities, etc.)

The best existing guide to federal mapproducing agencies in the United States is Walter Thiele's book, Official Map Publications. $^{1}$ The book does not attempt to list the maps published by each agency but describes the general nature of the maps available from each agency. Since his book was published, two new agencies which produce a considerable number of maps have come into existence, the Army Map Service and the Division of Cartography, State Department.

\section{U.S. Geological Survey}

In terms of numbers of different maps issued, four United States federal agencies are outstanding and some of their publications should be in any map library. The United States Geological Survey is responsible for the publication of the topographic map of the United States. ${ }^{2}$ This is the basic large-scale general map of the United States. It is for the most part on the scale of one inch to a mile, a scale large enough to show relief by means of detailed contours, all roads, and individual houses. This map and similar ones in other countries are really the base from which all accurate medium-scale maps must be made. The U.S.G.S. does not issue a catalog of its maps but it does issue a series of index maps for the various states, which indicate the sheets published. In addition it publishes base maps for the states on scales of I :500,000 and I : I,000,000.

This situation is indicative of conditions found in many other countries. There are probably at least fifty national survey or-

\footnotetext{
1 Thiele, Walter. Official Map Publications. Chicago, American Library Association, I938.

1 For a description of the mapping activities of the U.S.G.S., see Ibid., p. 121.27 .
}

ganizations which produce the basic general medium- and large-scale maps for their respective countries. Their name, however, will vary from country to country. ${ }^{3}$ In addition, their place within the administrative setup varies greatly. In some countries they are a part of the department responsible for domestic lands; in others they are under military supervision. Brief descriptions of the maps issued by these agencies for some of the more important countries can be found in several books. ${ }^{4}$ For the survey organizations of the smaller and less important countries no comprehensive list is available. In the average map library, however, there will be less need for detailed maps of Bulgaria and Liberia than there will be of France, England, and Canada. The librarian should realize that, if his map library plan prescribes medium- and largescale general map coverage in a particular country, national survey organizations similar to the United States Geological Survey will be the issuing agencies. Correspondence with individual foreign national survey agencies requesting a catalog or list and index maps which indicate the area covered by each sheet and the extent of the area for which coverage is available, is necessary. ${ }^{5}$ There is no short cut for this process and its advantages are several. From a comparison of the coverage planned and of the index and catalog information obtained, a

3 A few examples are Ordnance Survey of Great Britain, Reichamt für Landesaufnahme in Germany, Survey of India, and the Instituto Geografico Militare in Italy.

Thiele, op. cit., p. 119-281.

Olson, Everett C. and Whitmarsh, Agnes. Foreign Maps. New York, Harper, I944, o.195-23o.

5 Several factors explain the lack of collected index maps showing various map series for different countries of the world. The assembling alone, including infor mation, drafting, and printing, would be a monumental and expensive job. The changing situation with respect wation to lose its value rapidly. During the last war great strides were made in this field. The German army prepared comprehensive reports with index maps for each of the countries of Europe. Similar studies and extensive coverage indexes were made for large $\mathrm{sec}$ tions of the world by the Army Map Service and the Geograpical Section, General Staff of the United States Geographical Section, General Staff of the United St and unfortunate that both the quantity and distribution of these publications were limited. 
single order can be made for all material with its attendant purchasing economy. In addition, the catalog and index information will form in themselves an integral part of the map library files. The immediate need for many maps (particularly largescale general surveys) is questionable in the average college map library, but the map intelligence provided by the catalogs and indexes is important functional research information.

\section{Army Map Service}

A second important United States map publishing organization is the Army Map Service. $^{6}$ It is responsible for the preparation of the greater part of the maps needed by the War Department. The great variety of maps needed in modern warfare and the global nature of the last war suggest the scope of its map publications. It has been estimated that considerably more than a hundred thousand different maps were issued by the Army Map Service during the war. Its publications cover every country in the world and range from smallscale world maps to detailed surveys on large scales where actual ground operations were planned. They include beside general maps, a considerable variety of specialized maps. The greater part of these maps are either facsimile copies or simple recompilations of existing maps which were published by the national survey organizations of the countries involved. For example, the map service reissued the I : I,000,000, I :500,000, I :200,000, and I :50,000 sheets over parts of North Africa which were originally published by the French agency, Service Geographique de l'Armee, and by the local survey organizations of Algeria and Tun-

The Army Map Service was formed at the begin ning of World War II. lt was an outgrowth of the old Engineer Reproduction Plant, Corps of Engineers, War l)epartment. Today it is probably the largest and most complete map compilation and printing organization in the world.

isia. In Japan they reissued many of the I :50,000 series in facsimile with transliterated names, whereas the $I: 200,000$ and I : I,O0O,OOO series were completely redrawn at scales of I :250,000 and I I, 000,000 respectively.

Information concerning the map publications of the Army Map Service and their distribution is limited for military reasons. There has been a limited distribution of some of its maps, however, and the sale of some general smaller-scale series has been considered. The great majority of their maps will cover areas in the United States sphere of mapping responsibility. ${ }^{7}$ The publication by the Army Map Service of a catalog of maps which could be distributed and sold to the general public would be valuable. Meanwhile, the librarian can through correspondence ascertain which of the items in his map library plan are available. He should remember that the Army Map Service series may be either a facsimile or redraft of the organic series. As such it may be easier to obtain, easier to read because of translated legends, carry later information, and be cheaper per sheet than the organic series.

\section{Other Countries}

A counterpart of the Army Map Service exists or has existed in several of the more important countries and colonial powers. Prior to the last war the Geographical Section, General Staff (Great Britain), was outstanding. Its catalog listed small- and medium-scale series of areas all over the world where the British were economically interested or held sovereignty. The Service

\footnotetext{
7 The Army May Service and the Geographical Section, General Staff (Survey 1)irectorate, British Army) divided mapping responsibility. The U.S. was re sponsible for North Africa, southern Italy, parts of southern Germany and central Europe, China, and Japan. The Survey Directorates were responsible for the remaining areas of military operations. This the remaining areas of military operations. This division of labor refers to ground operations only. Both countries maintained their
scale series for air navigation.
} 
Geographique Nationale (formerly the Service Geographique de l'Armee) of France issued two catalogs, one listing domestic maps, the other maps for various parts of the world with special emphasis on French colonial possessions. To a lesser degree the Italian, German, and Japanese governments issued maps for areas outside of their national boundaries. ${ }^{8}$ At present, purchase of maps from these agencies is impossible, but should be feasible within a few years with the possible exceptions of Germany and Japan.

These agencies are particularly important to the map librarian, since they supply basic, original, general, small- and mediumscale coverage for many of the colonial areas and for the lesser developed areas of the world. ${ }^{9}$ In the future, their publications probably will provide supplemental coverage to that of local national survey organizations in certain critical or strategic military areas.

\section{Other Agencies}

The last two of the major federal mapmaking agencies are grouped together. Although the map publications of the United States Hydrographic Office and of the Coast and Geodetic Survey are, in the strictest sense, specialized in nature, their use for the average map library places them in the field of general maps. Designed as charts for navigation, they are specialized items. In a map library they are used commonly to provide general coverage over the areas

8 The Instituto Geographie Militaire, Firenze, issued a catalog listing single sheet and series maps for Italy proper as well as for her colonial possessions. The Reichamt fur Landesaufnahme still issued a few sheets Reichamt fur Landesaufnahme still issued a few sheets
for parts of China and Africa where the Germans had had colonial interests. During the war, however, the Kriegskarten und Vermessungwesen and Geo-Mil, which were the counterpart of the Army Map Service in the United States, issued thousands of maps for most of Europe and North Africa. Unfortunately most of these maps are lost to the world, although the bulk of them were reproductions of organic series.

8 The French and British organizations together covered all of Africa with a series of maps at $I: I, 000,000$. The British also published a series at the scale of $1: 1,000,000$ for eastern Asia and at $1: 4,000,000$ for all of Asia. The Army Map Service issued a series covering Central America at the scale of $1: 250,000$. adjacent to shore lines. The Coast and Geodetic Survey issues maps for the coasts of the United States and possessions, the Hydrographic Office for the coasts of remaining areas of the world. Thus, they do for the coasts and water areas of the world what the U.S. Geological Survey and the Army Map Service, respectively, do for the land areas of the world. Recently both agencies also have issued aeronautical charts over some of the areas for which they are responsible. The charts of the Hydrographic Office are of particular importance in providing coverage for smaller islands of the world, along the coasts of undeveloped lands where maps for the land areas may not be available, and for ports on a large scale. Both agencies issue excellent catalogs, well cross-referenced and with index maps. Associated with their chart activities, each issues some specialized maps related to navigation and of interest to many map libraries. Included are maps showing time zones, ocean currents, tides, winds, magnetic variation, and so forth.

Agencies with similar functions and map publications exist in about twenty countries. Most of these agencies have issued only a few charts and they pertain primarily to the national waters. The British Admiralty, however, issues an estimated three thousand different charts. A large number of these are reproduced in facsimile by the U.S. Hydrographic Office. Normally a map librarian will be able to fulfil the greater part of his coverage plans from the catalog of the U.S. Hydrographic Office. Only in a few instances, where he desires more detailed coverage in a foreign area, will he require foreign hydrographics.

From the foreign and domestic mapissuing agencies which have been described, practically all the large-, medium-, and small-scale general coverage needs can be met, for the whole world or parts of it, if 
the areas have been mapped. The maps published by these or similar official agencies are the foundation for any map library with general coverage facilities beyond that provided by atlas maps.

\section{Specialized Maps}

An analysis of official agencies producing specialized maps cannot be definitive. Specialized maps may be produced by departments, bureaus, and smaller subdivisions of federal administrative units. There may be as many as a hundred federal administrative units which have published at least one map. Some of them have produced a relatively large number; for example, the Bureau of Chemistry and Soils which publishes more than I 200 county soil maps, the Bureau of Reclamation, the Forest Service, and the Bureau of Agricultural Economics. For acquisition of such specialized material two procedures can be followed by the map librarian. First, examine carefully the subject price lists of the Superintendent of Documents in the field or subject for which specialized map material is desired. For example, if soil maps are needed, Price List 46, Agricultural Chemistry and Soils and Fertilizers has a complete list of the counties and areas for which soil maps are available. Price List 53, Maps, although not comprehensive, lists maps from several of the specialized map-issuing agencies such as the Bureau of the Census and the Bureau of Public Roads. Second, with the information gleaned from the price lists and other sources such as Thiele, write the government agency or agencies which are responsible for the subject material desired, requesting any additional specific information needed with relation to your map library plans. Blanket requests rarely will bring satisfactory results. Only requests based on a general knowledge of the agency's map publications and couched in terms of specific needs should be made. For ex- ample, the Bureau of Agricultural Economics has perhaps a thousand manuscript maps most of which have appeared in its serial and other publications. They pertain to a variety of items from crop and livestock distribution to value of farm lands and extent of animal diseases. The average map library will be interested in only such of these maps as fall within the scope of the plans formulated.

The complexity of the specialized map field illustrates concretely the need for clearcut objectives in terms of subjects for which map materials are needed. The indiscriminate collection of maps purely to acquire great numbers is futile.

Specialized map materials issued by state, county, and city agencies are limited and not widely publicized. The principal state agencies are the highway and agricultural departments, the geological surveys, and the public utility offices. Such agencies do not necessarily publish maps in every case, although each of the forty-eight states has issued a geological map. City and county map publications are apt to be beyond the scope of the average map library, except for material which pertains to the immediate vicinity of the library. Here the map library has an important archival function in preserving local map materials, both in published and manuscript form. These materials are highly fugitive and only local interests over a long period can collect and preserve them. The need for the assumption of such a function by local libraries was illustrated by the W.P.A. document surveys. State college and university libraries appear to be logical depository centers.

Specialized maps issued by official agencies in foreign countries, with the possible exception of the countries in western Europe, are far less in number and variety than those of the United States. Here the librarian must depend to a greater degree 
on professional journals and individuals versed in specialized fields. A sound knowledge of the functions of official map-issuing agencies in the United States and their place in the organizational framework of the federal government can be of considerable help in obtaining foreign materials. The similarity of the framework in foreign countries makes possible the application of the principles and experience gained with federal map-issuing agencies here. Even a large, backward country like China has its geological, meteorological, soil, and agricultural government organizations, although, with the possible exception of the first, their map publications are limited.

\section{Other Major Map Sources}

Commercial publishers or private agencies are the second major map source but in the aggregate are far less important than official agencies to the average map library. Most of their separate maps are on small scales and designed as wall maps (for instructional purposes and not for reference purposes) or for popular and commercial use. Maps of states and countries issued separately by them usually provide no more information than is available in large editions of standard atlases. This is especially true of their publications in the United States. Commercial concerns, however, are important as publishers of standard reference atlases, outline base maps, and supplementary, general, small-scale maps.

In foreign countries commercial map publishers are apt to be relatively more important in supplying needed coverage. In well-mapped countries where free road maps are not available and where the public is more map-conscious, commercial concerns issue excellent road, hiking, bicycle, and city maps. In poorly-mapped countries which lack active official mapping agencies (such as the Balkans, China, and Australia), commercial companies are relatively important. For example, in Greece the best topographic map of the country, which has a scale of $I: 200,000$, is issued by a private concern.

The number of these concerns, both foreign and domestic, is not great. Some of them are known widely, such as John Bartholomew in Great Britain, Justus Perthes in Germany, Freytag and Berndt in Austria, and Rand McNally in the United States. Catalogs and information concerning map publications of these and other commercial concerns are easier to obtain than from official agencies. Specific names can be obtained either from bibliographic lists or, in the case of a particular country, from its officials in this country.

\section{Scientific Societies}

The last of the major sources of maps are the scientific societies and institutes. Their maps are largely of a specialized nature related to their activities. They supplement specialized maps issued by government agencies and are relatively more important to the average map library than their number would indicate. They are difficult to acquire because of their specialized nature, covering a wide range of subjects, issued by a variety of organizations, and because of the irregular and infrequent intervals of publication. Many of their maps may be issued in conjunction with their publications as well as separately.

In some cases the projects undertaken are monumental in scope, such as the map of Hispanic America ( $1: 1,000,000)$ requiring more than one hundred sheets, which was completed recently by the American Geographical Society after nearly twenty years' work. In other cases only a few maps have been issued, such as the tectonic and geological maps of North and South America published by the Geological Society of America. In foreign countries such organizations may have a quasi-official position, 
for example, the organization which issued the excellent National Atlas of France and the Societe d'Editions Geographiques, Maritimes, et Coloniales which published the Atlas des Colonies Francaises.

In acquiring material from these sources the map librarian is faced with a situation similar to that in obtaining specialized maps from official agencies. He can depend in part on map bibliographies, but a greater degree of dependence must be placed on professional journals and individuals in the field of the subject matter involved.

\section{Books on Mapping Services}

There are relatively few books on mapping services in various countries. Several books are invaluable, however, to the map librarian who is interested in modern map sources. Outstanding among these is Thiele, Official Map Publications. ${ }^{10}$ It contains a brief and excellent summary of each of the United States governmental mapping services with a reference list of their map publications or notes as to their nature. Chapters are devoted to Latin America, Great Britain, Germany, and a group of smaller countries. The only serious deficiency of the book, besides its limited coverage, is its lack of index maps. Nevertheless, it offers the map librarian sufficient information and background in those areas described to initiate a purchasing program according to his needs. The most comprehensive map catalog issued covers South America. The Catalogue of Maps of Hispanic America lists not only separately published maps but also those published in books and periodicals. ${ }^{11}$ Unfortunately, the publication is now more than fifteen years old, although it may be supplemented by the summaries on cartography in the annual

\footnotetext{
10 Thiele, op. cit.

11 American Geographical Society. Catalogue of Maps of Hispanic America. New York, American Geographi-
} cal Society, r 933 . volumes of the Handbook of Latin American Studies. Additional publications provide only fragmentary information, but two in particular should be mentioned. Olson and Whitmarsh, Foreign Maps gives brief summaries of the more important map series for about forty countries and lists some of the outstanding government map catalogs. ${ }^{12}$ Hinks, Maps and Survey devotes space to a comparative analysis of some of the European series which is helpful in their evaluation. ${ }^{13}$

\section{Building a Background}

Difficulties outlined in the brief description and analysis of map sources should not discoutage librarians. With experience one develops the same "bibliographic feel or sense" as with books. One of the best ways of building a background of map sources is through constant inspection of the reviews and notes in geographical journals. They provide the most complete information concerning current general and specialized maps. The two more useful current lists, which are based on new maps received at the American Geographical Society and the Royal Geographical Society, are The Geographical Record (mimeographed) and "The Supplement" to the Geographical Journal respectively. Prior to the last war a useful monthly list also appeared in Petermanns Mitteilungen. Supplementing these lists are the reviews of new maps and notes or articles concerning the mapping situation in various countries which appear in pro. fessional geographical journals such as the Geographical Review and surveying or mapping journals such as the Empire Survey Review and Surveying and Mapping. As these publications are examined, acquisitions which fit into the plans formulated can be made. This method also provides

12 Olson and Whitmarsh, op. cit.

13 Hinks, Arthur R. Maps and Survey, 4th ed. Cam. bridge, University Press, 1942. 
an excellent way to maintain, by addition of new sheets or editions, map series which may already be on hand. The knowledge acquired of map sources and of the scope of map materials available will be of considerable value in planning and making purchases to cover specific areas.

The development and maintenance of a college map library of modest size cannot be left to incidental purchases based on suggestions by faculty members over a period of time. The previous discussion of map sources which illustrated their documentary and fugitive nature shows that an adequate and balanced working collection can be obtained only if a definite plan as to its nature and scope is formulated and only if that plan is administered by an individual who is interested in and responsible for it. The peculiarities of map publications are such that the adequacy of a given map collection is largely a measure of the ability of the librarian responsible for it. A librarian with considerable geographic training will usually be more successful than one without such a background. Training in geography helps to provide a knowledge of spatial relationships which is necessary to an evaluation of map materials. It develops an appreciation of the distributional patterns of phenomena for which map coverage is desirable and it supplies an introduction to the geographical materials from which map information is obtained.

\section{The Recataloging Program of the Army Medical Library}

\section{(Continued from page 44)}

Library, the former series of SG cards was discontinued, and a new series with numbers preceded by MED was begun. In order that medical libraries which might desire to place a subscription to the whole series could obtain cards for all medical books added to the national libraries, the
Library of Congress asked that its own cataloging of medical titles be included in the same series. The first copy for this new departure in cooperative cataloging was sent to the Library of Congress, Oct. I, 1946. Since then cards of the MED series have appeared in increasing numbers. 